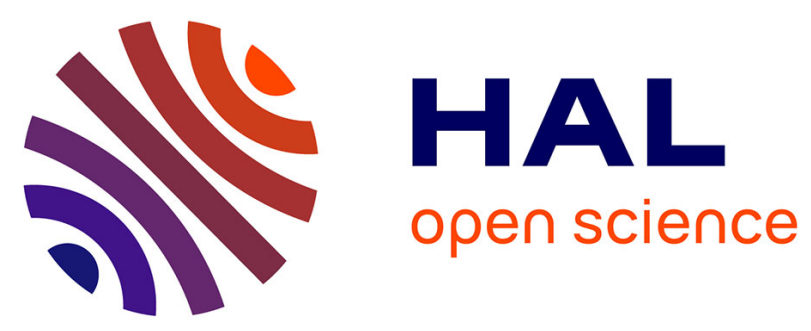

\title{
Design of an Algebraic Concept Operator for Adaptive Feedback in Physics
}

\author{
Andrew Thomas Bimba, Norisma Idris, Ahmed A. Al-Hunaiyyan, Rohana \\ Binti Mahmud, Nor Liyana Bt Mohd Shuib
}

\section{- To cite this version:}

Andrew Thomas Bimba, Norisma Idris, Ahmed A. Al-Hunaiyyan, Rohana Binti Mahmud, Nor Liyana Bt Mohd Shuib. Design of an Algebraic Concept Operator for Adaptive Feedback in Physics. 17th Conference on e-Business, e-Services and e-Society (I3E), Oct 2018, Kuwait City, Kuwait. pp.181-190, 10.1007/978-3-030-02131-3_17. hal-02274143

HAL Id: hal-02274143

https://hal.inria.fr/hal-02274143

Submitted on 29 Aug 2019

HAL is a multi-disciplinary open access archive for the deposit and dissemination of scientific research documents, whether they are published or not. The documents may come from teaching and research institutions in France or abroad, or from public or private research centers.
L'archive ouverte pluridisciplinaire HAL, est destinée au dépôt et à la diffusion de documents scientifiques de niveau recherche, publiés ou non, émanant des établissements d'enseignement et de recherche français ou étrangers, des laboratoires publics ou privés.

\section{(c)(1)}

Distributed under a Creative Commons Attribution| 4.0 International License 


\title{
Design of an Algebraic Concept Operator for Adaptive Feedback in Physics ${ }^{\star}$
}

\author{
Bimba Andrew Thomas ${ }^{1}$, Norisma Idris ${ }^{1}$, Ahmed A. Al-Hunaiyyan ${ }^{2}$, Rohana \\ Binti Mahmud ${ }^{1}$, and Nor Liyana Bt Mohd Shuib ${ }^{3}$ \\ 1 Department of Artificial Intelligence, University of Malaya, Kuala Lumpur, \\ Malaysia \\ 2 Computer \& Information Systems Department, College of Business Studies, The \\ Public Authority for Applied Education \& Training (PAAET), Kuwait City, Kuwait \\ 3 Department of Information Systems, University of Malaya, Kuala Lumpur, \\ Malaysia
}

\begin{abstract}
In an adaptive learning environment, the feedback provided during problem-solving requires a means, target, goal, and strategy. One of the challenges of representing feedback to meet these criteria, is the representation of the effect of multiple concepts on a single concept. Currently, most of the methods (linguistic knowledge base, expert knowledge base, and ontology) used in representing knowledge in an adaptive learning environment only provide relationships between a pair of concept. However, a cognitive knowledge base which represents a concept as an object, attribute, and relations (OAR) model, provides a means to determine the effect of multiple concepts on a single concept. Using the OAR model, the relationships between multiple pedagogical, domain, and student attributes are represented for providing adaptive feedback. Most researchers have proposed adaptive feedback methods that are not fully grounded in pedagogical principles. In addition, the three knowledge components of the learning environment (pedagogical, domain and student models) are mostly treated in isolation. A reason for this could be the complex nature of representing multiple adaptive feedback characteristics across the main components of a learning environment. Thus, there is a need to design a concept operator that can relate the three facets of knowledge in an adaptive learning environment. Using the algebraic concept operator $R_{i}^{i n}$, the effect of multiple attributes of the three knowledge components on the student's performance is represented. The algebraic concept operator introduced in this article will allow teachers and pedagogy experts to understand and utilize a variety of effective feedback approaches.
\end{abstract}

Keywords: OAR Model · Knowledge Base · Pedagogy · Learning Environment $\cdot$ Student $\cdot$ Problem Solving

* Supported by University of Malaya Research Grant [RP040B-15AET, 2015]. 


\section{Introduction}

In an adaptive learning environment, the feedback provided during problemsolving requires a means, target, goal, and strategy [1]. One of the challenges of representing feedback to meet these criteria, is the representation of the effect of multiple concepts on a single concept. Currently, most of the methods (linguistic knowledge base, expert knowledge base, and ontology) used in representing knowledge in an adaptive learning environment only provide relationships between a pair of concept [2. However, a cognitive knowledge base which represents a concept as an object, attribute, and relations (OAR) model, provides a means to determine the effect of multiple concepts on a single concept. Using the OAR model, the relationships between multiple adaptive feedback means, target, goal, and strategy are represented for providing adaptive feedback by showing the effect of these characteristics on the performance of the student. The proposed concept operator is initialized using randomly pre-configured relationships between the characteristics of the pedagogical, domain and student model. During the process of learning, these relationships are automatically updated to suggest the appropriate combination of adaptive feedback means, target, goal, and strategy which can lead to optimal performance for different students.

Knowledge in a adaptive learning environment can be represented in the form models. The three most important models are the pedagogical model, domain model, and the student model. The pedagogical model represents the knowledge and technique of teaching. Specific knowledge represented in the pedagogical model is based on a pedagogical principle or learning theory. This principle or theory determines the effective teaching methods, instructional methods, sequence of activities, feedback types, and assessments modeled by the learning environment. On the other hand, the domain model, is a facet of the pedagogical model, which represents the knowledge of the subject been learned. The domain model represents concepts, learning materials, facts, problems, solutions, feedback, rules, equations etc. Finally, the student model represents information about the student's knowledge of the domain, learning style, interactions with the system, response to feedback, emotional state, performance etc. These information determines the characteristics of the student during problem-solving.

[10] defines a problem as an obstacle between a present state and a goal and it is not immediately obvious how to get around the obstacle (p. 365). Two types of problems identified by Psychologists are well-structured and ill-structured problems. The well-structured, are problems that by applying certain procedures will lead to a correct answer, while ill-defined problems do not usually have a single correct answer and have an unclear process to arriving at a solution [1617. Depending on the type of problem considered, the Novice tends to be more accurate when the problem at hand is well-structured, but in cases where the problems are ill-structured, the Novice tends to perform poorly [3]12]17|18 19|10|8]. This could be related to the fact that the Novice has little knowledge of the deep structure of the problem, thereby not understanding the under-lining principles and concepts related to such problems. Physics instructions are designed to help 
students improve their problem solving expertise [19]. This is why some physics problems are ill-structured, similar to most real-life and professional problems.

Physics is more closely associated to everyday experiences. Thus, having proficiency in physics is a relevant skill, which can be extended to solving everyday problems. Physics is generally regarded as a difficult subject. Factors contributing to this difficulty include: 1) the presence of misconceptions; 2) degree of logical precision and reasoning required; 3) mathematical skills required; 4) misinterpretation of question posed; 5) concept gaps; and 6) knowledge gaps [19]5]. During physics problem-solving in an adaptive learning environment, feedback is provided to assist the student in achieving a set objective.

Most researchers have proposed adaptive feedback methods that are not fully grounded in pedagogical principles [915. In addition, the three main knowledge components of the learning environment (pedagogical, domain and student model) are mostly treated in isolation. A reason for this could be the complex nature of representing multiple adaptive feedback characteristics across the main components of a learning environment. Thus, there is a need to design a concept operator that can relate the three facets of knowledge in an adaptive learning environment.

The article is structured into 5 sections. First, feedback in an adaptive learning environment is introduced in section 1 and a brief background on pedagogy and student modeling is presented in section 2 . In section 3 , we explain the design of an algebraic concept operator for adaptive feedback. Preliminary results, on the implementation of the algebraic concept operator is presented in section 4. And finally, in section 5 we conclude the article and highlight the future works.

\section{Background}

Educational institutions are relatively successful in arranging and conveying large forms of knowledge and standard pedagogical practices [6]13. However, little attention is paid to the strategies experts use to acquire knowledge in solving complex task. The emphasis, in educational institutions is mostly on formulaic methods for solving textbook problems. While few resources are devoted to high-order problem-solving which requires students to actively integrate and apply conceptual knowledge. In order to make a positive impact on student's skill acquisition, there is a need to understand how experts acquire skills and to formulate different methods that are appropriate to learning these skills [6]. Therefore, more effort should be made on recognizing cognitive and metacognitive strategies rather than low-level sub-skills and factual knowledge. To support student learning, teachers and educationists regularly use a wide range of educational theories and teaching strategies [20. Over the past decades, researchers have developed various learning theories in an attempt to explain how knowledge is acquired. These include theories such as behaviorism, cognitivism, and constructivism. The cognitive approach places the learner and the internal mental processes at the center of teaching. Because cognitivism focuses on revealing the various processes involved in knowledge acquisition, thereby providing 
strategies that support students learning, tutors can utilize this in their effort to aid students in attaining their goals. The cognitive apprenticeship (CA) instructional approach utilizes cognitive and meta-cognitive skills and processes to guide learning [7]. The CA concept is defined by [6] as learning through guided experience, cognitive and meta-cognitive skills rather than physical skills and processes as in traditional apprenticeship. In CA learning environment, students cannot engage in the apprenticeship process alone, rather it involves modeling (demonstration by expert) and coaching in the initial stage of learning [7]. The CA model for designing learning environments has four dimensions: i) content or domain (the type of knowledge required for expertise), ii) method (teaching method to promote student development), iii) sequencing (ordering learning activities), and iv) sociology (social characteristics of the learning environment) [6]14].

The selection of appropriate student's characteristics is significant in the early stages of developing a student model. It is important to consider what aspect of the student characteristics is to be modeled according to the type of system developed [11]. In order to implement adaptation in a learning environment it is necessary to model the flexibly stable, dynamic and domain dependent characteristics of the student 44. The flexibly stable characteristics of the student includes cognitive styles, student's demographics, learning objectives and goals. The dynamic parameters are concerned with the students interactions and experience with the learning environment. These characteristics include the student's errors and mis-conceptions, motivations, attitude, collaboration, learning actions and behaviors. The domain dependent characteristics of the student involves the student's knowledge level and interest in a specific topic.

The development of an adaptive feedback environment requires the combination of pedagogical principles, domain attributes and various student's characteristics. This research emphasizes on the cognitive apprenticeship principle. The attributes of the students considered for adaptive feedback are the cognitive learning style, student's performance, and knowledge level. The cognitive apprenticeship approach to learning involves the guidance of a student to achieve cognitive and meta-cognitive skills with the help of an expert. This principle was selected for this research because it clearly supports feedback, thus providing an avenue to demonstrate the use of a dynamic knowledge base approach to adaptive feedback.

\section{Algebraic Concept Relations for Adaptive Feedback in Physics}

In this article, we focus on the cognitive apprenticeship (CA) pedagogical principle and the physics domain. In a CA principle, the main aim of designing teaching methods is to help students acquire and use cognitive and meta-cognitive strategies for discovering, utilizing and managing knowledge [6]. The acquisition and use of these strategies solely depends on the interaction between the student's current knowledge, the social and physical environment of the problem-solving 
and the intricacies of the problem-solving. The challenge is to represent the attributes of the CA principle that affect the type, timing, goal, and sequence of feedback, relating it to the characteristics of the domain and student models. The representation of the characteristics of all 3 models relating to adaptive feedback is shown in Fig. 1. The knowledge in the proposed pedagogy, domain, learner - cognitive knowledge base (PDL-CKB) model is based on the OAR model. The nodes of the concept network in Fig. 1. represents concepts in the pedagogy, domain and student model in an adaptive learning environment. The arcs represent the relationship between concepts and their attributes.

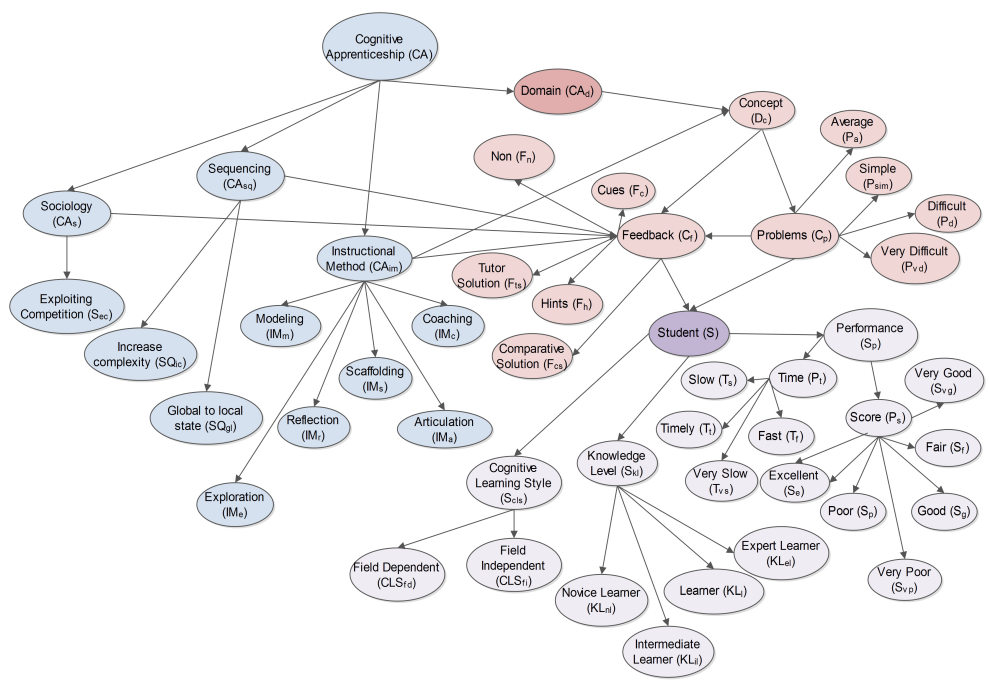

Fig. 1. PDL-CKB Model for Adaptive Feedback in Physics

An algebraic concept relation which provides adaptive feedback in physics is proposed. The main objective is to observe the relationship between the performance of a student based on the adaptive feedback provided. However, the adaptive feedback provided depends on the adaptive feedback means, goal, target, and strategy. These involves the 3 facet of the adaptive learning environment of pedagogy, domain, and student models. The effect of multiple concepts on a single concept is defined in Eq. 1].

$$
R_{i}^{i n} \subseteq \bigcup_{i=1}^{\left|R_{i}\right|} R_{i}^{c}
$$


The effect of a concept is represented as the union between all its related external concepts as shown in Eq. 1.

where

- $R_{i}^{c}$ is the internal relationships that exist between multiple concept that have a relation or effect on the current concept concerned.

For example, in an adaptive learning environment as shown in Figure 1 the effect of the attributes of concepts within the pedagogy, domain, and student models on the performance of the student is represented in Eq. 2

$$
R_{p}^{i n} \subseteq\left(R_{C A}^{c} \cup R_{C A_{d}}^{c} \cup R_{S}^{c}\right)
$$

where

- $R_{C A}^{c} \subseteq\left(C A_{s} \cup C A_{s q} \cup C A_{i m}\right)$ is the union of active sets of attributes within the pedagogical model which are related to the performance of a student at a given time.

- $R_{C A_{d}}^{c} \subseteq\left(D_{c} \cup C_{f} \cup C_{p}\right)$ is the union of active sets of attributes within the domain model which are related to the performance of a student at a given time.

- $R_{S}^{c} \subseteq\left(S_{c l s} \cup S_{k l}\right)$ is the union of active sets of attributes within the student model which are related to the performance of a student at a given time.

By expanding Eq. 2, all possible relationships between the performance of a student and the attributes of pedagogical, domain, and student model is presented in Eq. 3

$$
\begin{array}{r}
R_{s_{p}}^{i n} \subseteq\left\{\left\{S_{e c}\right\} \cup\left\{\left\{S Q_{i c}, S Q_{g l}\right\} \cup\left\{I M_{m}, I M_{c}, I M_{s}, I M_{r}, I M_{a}, I M_{e}\right\}\right\}\right. \\
\cup\left\{\left\{F_{t s}, F_{h}, F_{c}, F_{n}\right\} \cup\left\{D_{c}\right\} \cup\left\{P_{s i m}, P_{a}, P_{d}, P_{v d}\right\}\right\} \\
\left.\cup\left\{\left\{C L S_{f d}, C L S_{f i}\right\} \cup\left\{K L_{n l}, K L_{i l}, K L_{l}, K L_{e}\right\}\right\}\right\}
\end{array}
$$

During the learning process, not all attributes are activated at the same time. For example, a student cannot be a FI and FD learner at the same time. Therefore, at any given time (t), the effect of multiple concepts on the performance of a student can be represented as shown in Eq. 4 .

$$
\begin{gathered}
R_{s_{p}}^{i n} \subseteq\left\{\left\{S Q_{i c}, I M_{m}\right\} \cup\left\{F_{t s}, D_{c}, P_{s i m}\right\} \cup\left\{C L S_{f d}, K L_{n l}, K L_{i l}, K L_{l}, K L_{e}\right\}\right\} \\
R_{s_{p}}^{i n} \subseteq\left\{S Q_{i c}, I M_{m}, F_{t s}, D_{c}, P_{s i m}, C L S_{f d}, K L_{n l}\right\}
\end{gathered}
$$

Using Eq. 5. the performance of a novice student $K L_{n l}$ with a field Dependant cognitive learning style $C L S_{f d}$, solving a simple problem $P_{s i m}$ within a domain concept $D_{c}$, provided with an increasing complexity of feedback $S Q_{i c}$ in a modeling stage $I M_{m}$ can be easily represented. Thus, the system can automatically analyze the right combination of characteristics of the pedagogy, 
domain, and student models which provides the best performance for different type of students at different knowledge levels. In an adaptive feedback perspective, this implies an automatic update of the knowledge base, based on the best performance of different students solving different problems and receiving different feedbacks according to their individual characteristics and knowledge level on a specific concept. The proposed adaptive feedback model allows the knowledge base to make an automatic decision on the function, time, schedule, and type of feedback provided. At an initial state of building the knowledge base the knowledge bonding process selects random combinations of the required attributes needed to provide adaptive feedback to the student. As more students use the system, the knowledge base learns and updates its optimum combination of concepts to achieve an effective feedback to the student.

\section{Preliminary Results}

The provision of feedback based on the cognitive apprenticeship principle involves the instructional method, sequencing, sociology, and domain. When providing feedback in this context, a decision has to be made on what instructional method to be applied, the sequencing, and the application of a sociological component. In Table 1, a summary of the different forms of feedback provided based on the CA principle is presented. Certain interventions can be provided to the student before and during problem solving in a specific sequence. As seen in Table 1. there are 17 possible forms of feedbacks to be provided based on the feedback model presented in Fig. 1. The feedback attributes as shown in Table 1 are the characteristics of the CA pedagogical principle that determine the type of feedback that will be provided before and during problem-solving.

In the process of solving a problem there are different scenarios based on the domain attributes such as topic and problem and also the characteristics of the students which includes cognitive learning style and knowledge level. Based on these characteristics a total of 408 problem solving states are possible. In table 2. a summary of these problem solving states are presented. As students solve problems, they receive feedback based on the pedagogical principles and their performance is feedback to the knowledge base according to the current problem solving state. These allow the knowledge base to be dynamic and the choice of feedback is based on the algebraic concept operation $R_{p}^{i n}$ defined. 
Table 1. Type of Feedback based on the Cognitive Apprenticeship Principle.

\begin{tabular}{|c|c|c|c|c|c|}
\hline $\mathrm{S} / \mathrm{N}$ & Feedback ID & Feedback Attributes & $\begin{array}{l}\text { Before } \\
\text { Problem-solving }\end{array}$ & $\begin{array}{l}\text { During } \\
\text { Problem-solving }\end{array}$ & Timing \\
\hline 1 & FT1 & $\begin{array}{l}\text { exploiting competition, } \\
\text { global to local state, modelling }\end{array}$ & $\begin{array}{l}\text { student's } \\
\text { worked-example }\end{array}$ & student's solution & immediate, after first error \\
\hline 2 & FT2 & $\begin{array}{l}\text { exploiting competition, } \\
\text { modelling, increase complexity }\end{array}$ & $\begin{array}{l}\text { student's } \\
\text { worked-example }\end{array}$ & $\begin{array}{l}\text { hints, clues, } \\
\text { student's explanation }\end{array}$ & immediate, after each error \\
\hline 3 & FT3 & modelling,global to local state & tutor's solution & tutor's worked-example & immediate, after first error \\
\hline 4 & FT4 & increase complexity, modelling & tutor's solution & $\begin{array}{l}\text { hints, cues, } \\
\text { tutor's explanation }\end{array}$ & immediate, after each error \\
\hline 5 & FT5 & global to local state, scaffolding & non & $\begin{array}{l}\text { tutor's partial } \\
\text { worked-example }\end{array}$ & $\begin{array}{l}\text { immediate, after more than one error. } \\
\text { Provide feedback not more than twice. }\end{array}$ \\
\hline 6 & FT6 & $\begin{array}{l}\text { increase complexity, } \\
\text { scaffolding }\end{array}$ & non & $\begin{array}{l}\text { hints, cues, } \\
\text { tutor partial explanation }\end{array}$ & $\begin{array}{l}\text { immediate, after each error. Provide } \\
\text { feedback not more than twice. }\end{array}$ \\
\hline 7 & FT7 & $\begin{array}{l}\text { exploiting competition, } \\
\text { global to local state, scaffolding }\end{array}$ & non & $\begin{array}{l}\text { student's partial } \\
\text { worked-example }\end{array}$ & $\begin{array}{l}\text { immediate, after first error. Provide } \\
\text { feedback not more than twice. }\end{array}$ \\
\hline 8 & FT8 & $\begin{array}{l}\text { exploiting competition, } \\
\text { increase complexity, scaffolding }\end{array}$ & non & $\begin{array}{l}\text { hints, cues, student's } \\
\text { partial explanation }\end{array}$ & $\begin{array}{l}\text { immediate, after each error. Provide } \\
\text { feedback not more than twice. }\end{array}$ \\
\hline 9 & FT9 & $\begin{array}{l}\text { exploiting competition, } \\
\text { global to local state, coaching }\end{array}$ & non & $\begin{array}{l}\text { student's } \\
\text { worked-example }\end{array}$ & immediate, after first error \\
\hline 10 & FT10 & $\begin{array}{l}\text { exploiting competition, } \\
\text { increase complexity, coaching }\end{array}$ & non & $\begin{array}{l}\text { hints, cues, } \\
\text { student's explanation }\end{array}$ & immediate, after each error \\
\hline 11 & FT11 & $\begin{array}{l}\text { global to local state, } \\
\text { coaching }\end{array}$ & non & $\begin{array}{l}\text { tutor's } \\
\text { worked-example }\end{array}$ & immediate, after first error \\
\hline 12 & FT12 & $\begin{array}{l}\text { increase complexity, } \\
\text { coaching }\end{array}$ & non & $\begin{array}{l}\text { hints, cues, } \\
\text { tutor's explanation }\end{array}$ & immediate, after first error \\
\hline 13 & FT13 & $\begin{array}{l}\text { increase complexity, } \\
\text { exploiting competition, } \\
\text { articulation }\end{array}$ & non & student's explanation & at the end of problem-solving \\
\hline 14 & FT14 & $\begin{array}{l}\text { increase complexity, } \\
\text { articulation }\end{array}$ & non & tutor's explanation & at the end of problem-solving \\
\hline 15 & FT15 & $\begin{array}{l}\text { global to local state, } \\
\text { reflection }\end{array}$ & non & $\begin{array}{l}\text { tutor's } \\
\text { worked-solution }\end{array}$ & at the end of problem-solving \\
\hline 16 & FT16 & $\begin{array}{l}\text { global to local state, } \\
\text { exploiting competition, } \\
\text { reflection }\end{array}$ & non & $\begin{array}{l}\text { student's } \\
\text { worked-solution }\end{array}$ & at the end of problem-solving \\
\hline 17 & FT17 & exploration & non & non & result at the end of problem-solving \\
\hline
\end{tabular}


Table 2. Relationship between students performance and pedagogy, domain, and student attributes

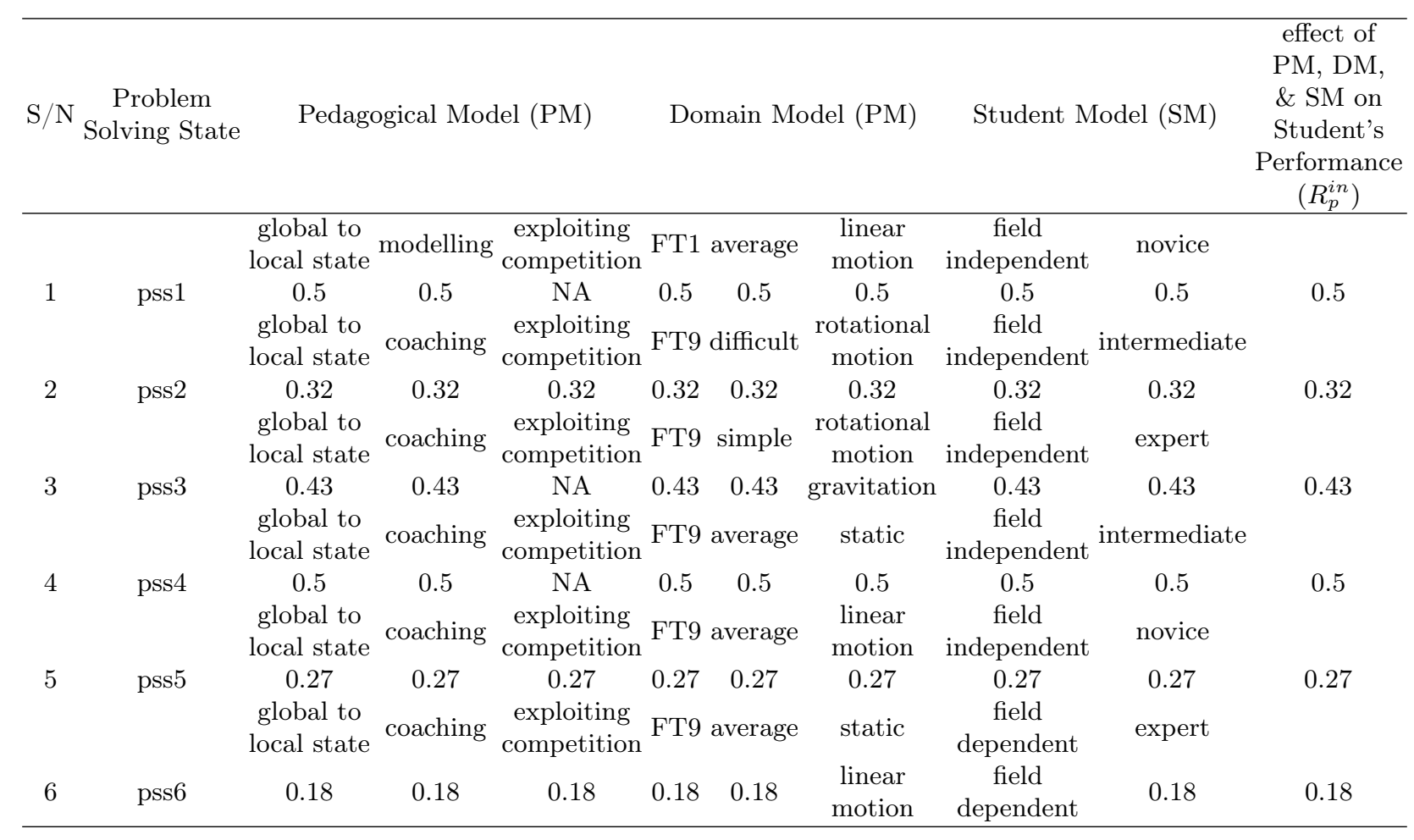




\section{Conclusion}

The aim of this article is to present the design of an algebraic concept operator which represents the relationship between student's performance and multiple attributes in the pedagogy, domain and student models. Fig. 1, represents the relationship between the 3 facets (pedagogy, domain, and student models) of an adaptive learning environment. The model shows how full adaptive feedback characteristics can be modeled in the physics domain. It shows how concept algebra is applied to designing a concept association operator which defines the effect of multiple concepts on a single concept. Based on the preliminary results, about 17 adaptive feedback scenarios based on the cognitive apprenticeship principle are defined. Using the algebraic concept operator $R_{p}^{i n}$, the effect of multiple attributes of the pedagogy, domain, and student models on the student's performance is represented. These allows a selection of a effective adaptive feedback to be provided to the student during problem-solving. The algebraic concept operator introduced in this article will provide developers of adaptive learning environments with a means capturing effective relationships between multiple attributes in the pedagogy, domain, and student models. In addition it allows teachers and pedagogy experts to understand and utilize a variety of effective feedback approaches. In the future, a learning algorithm will be included to allow adjustments in the weights between the related concepts in the pedagogy, domain, and student models.

\section{References}

1. Bimba, A.T., Idris, N., Al-Hunaiyyan, A., Mahmud, R.B., Shuib, N.L.B.M.: Adaptive feedback in computer-based learning environments: a review. Adaptive Behavior 25(5), 217-234 (2017). https://doi.org/10.1177/1059712317727590, https : //doi.org/10.1177/1059712317727590

2. Bimba, A.T., Idris, N., Mahmud, R.B., Al-Hunaiyyan, A.: A cognitive knowledgebased framework for adaptive feedback. In: International Conference on Computational Intelligence in Information System. pp. 245-255. Springer (2016)

3. Chi, M.T.H., Feltovich, P.J., Glaser, R.: Categorization and representation of physics problems by experts and novices. Cognitive science 5(2), 121-152 (1981)

4. Chrysafiadi, K., Virvou, M.: Student modeling approaches: A literature review for the last decade. Expert Systems with Applications 40(11), 4715-4729 (2013)

5. Clement, J.: StudentsâĂŹ preconceptions in introductory mechanics. American Journal of physics 50(1), 66-71 (1982)

6. Collins, A., Brown, J.S., Newman, S.E.: Cognitive apprenticeship: Teaching the crafts of reading, writing, and mathematics. Knowing, learning, and instruction: Essays in honor of Robert Glaser 18, 32-42 (1989)

7. Dennen, V.P., Burner, K.J.: The cognitive apprenticeship model in educational practice. Handbook of research on educational communications and technology $\mathbf{3}$, 425-439 (2008)

8. Docktor, J.L., Mestre, J.P., Ross, B.H.: Impact of a short intervention on novicesâĂŹ categorization criteria. Physical review special topics-physics education research 8(2), $020102(2012)$ 
9. Gerdes, A., Jeuring, J., Heeren, B.: An interactive functional programming tutor. In: Proceedings of the 17th ACM annual conference on Innovation and technology in computer science education. pp. 250-255. ACM (2012)

10. Goldstein, E.B.: Cognitive psychology: Connecting mind, research and everyday experience. Nelson Education (2014)

11. GonzÃąlez, C., Burguillo, J.C., Llamas, M.: A qualitative comparison of techniques for student modeling in intelligent tutoring systems. In: Frontiers in Education Conference, 36th Annual. pp. 13-18. IEEE (2006)

12. Hardiman, P.T., Dufresne, R., Mestre, J.P.: The relation between problem categorization and problem solving among experts and novices. Memory \& Cognition 17(5), 627-638 (1989)

13. Paul, B.: Helping students to become capable learners. European Journal of Education 53(2), 144-159 (2018). https://doi.org/10.1111/ejed.12273, https:// onlinelibrary.wiley.com/doi/abs/10.1111/ejed.12273

14. Polo, F.G.: Using the cognitive apprenticeship model to develop educational learning modules: An example from statics. In: 122nd American Society for Engineering Education Conference and Exposition, Seattle, WA (2015)

15. Rivers, K., Koedinger, K.R.: Data-driven hint generation in vast solution spaces: a self-improving python programming tutor. International Journal of Artificial Intelligence in Education 27(1), 37-64 (2017)

16. Shekoyan, V., Etkina, E.: Introducing illâǍ physics recitations. In: AIP Conference Proceedings. vol. 951, pp. 192-195. AIP (2007)

17. Shin, N., Jonassen, D.H., McGee, S.: Predictors of wellâĂŘstructured and illâǍ $\breve{R s t r u c t u r e d ~ p r o b l e m ~ s o l v i n g ~ i n ~ a n ~ a s t r o n o m y ~ s i m u l a t i o n . ~ J o u r n a l ~ o f ~ r e s e a r c h ~}$ in science teaching 40(1), 6-33 (2003)

18. Singh, C.: Categorization of problems to assess and improve proficiency as teachers and learners. American Journal of Physics 77(1), 73-80 (2009)

19. Soong, B., Mercer, N., Er, S.S.: StudentsâĂŹ difficulties when solving physics problems: Results from an ict-infused revision intervention. In: Proceedings of the 17th International Conference on Computers in Education (ICCE). pp. 361-365 (2009)

20. Tompkins, E.K.: Application of cognitive apprenticeship model (ca) to library instruction. College \& Undergraduate Libraries 23(1), 1-15 (2016) 